\title{
Moralidade e risco na interface médico-paciente na perícia médica da Previdência Social
}

\author{
| ${ }^{1}$ Maria da Penha Pereira de Melo |
}

Resumo: Uma dupla vulnerabilidade, doença e incapacidade para o trabalho: essa é a condição que deverá ser verificada pelos médicos peritos da Previdência Social entre os que solicitam o benefício auxílio-doença. Em uma sociedade organizada em torno da produção e consumo de bens, a ausência de rendimentos quase sempre significa o rebaixamento social e a privação. No contexto previdenciário, o ato médico ocorre sem que a conduta esteja voltada para o restabelecimento da saúde, tratamento ou prevenção do adoecimento, mas a ausência do compromisso assistencial seria suficiente para prescindirmos do exame moral dessa interface? Este artigo desenvolve o argumento de que a atividade médico-pericial de controle sobre a entrada e/ou permanência em auxílio-doença envolve um tipo específico de risco que decorre da singularidade da tarefa de controle. Nesta o compromisso com o paciente, ou pessoa em sofrimento, típico da medicina, é deslocado em decorrência da necessidade de controle do acesso ao benefício. Entre a beneficência para com o demandante e o interesse coletivo de preservar recursos pela observância estrita do regramento previdenciário, há um espaço discricionário preenchido pela atividade médica, o espaço de arriscar-se, de tensionamento e, por vezes, de disfunçōes. A especialização em reconhecer a incapacidade laborativa é moralmente conflitiva. A reflexão ativa e o julgamento consciencioso não eliminam o risco moral, mas tornam mais evidentes as condiçōes de sua emergência e a necessidade de considerá-lo seriamente ao lidar com essas práticas de controle sobre a população.
${ }^{1}$ Médica sanitarista; mestre em Saúde Pública pela Universidade Federal de Minas Gerais; doutoranda do Programa de Pós-graduação em Bioética, Ética Aplicada e Saúde Coletiva (PPGBIOS). Supervisor Médico Pericial, Instituto Nacional do Seguro Social. Rio de Janeiro, Brasil. Endereço eletrônico: penh@ig.com.br 


\section{Introdução}

Dupla vulnerabilidade, doença e incapacidade para o trabalho: essa é a condição em que se encontram os que solicitam o benefício auxílio-doença da Previdência Social. Melhor dizendo, essa é a condição que deverá ser verificada pelos médicos peritos da Previdência Social para que o benefício seja concedido ou mantido. Somente em 2011, foram realizados 7,3 milhões de exames médico-periciais (BRASIL, 2011).

O bem protegido nesta modalidade de benefício é a capacidade de obter renda a partir do trabalho, da atividade econômica. É a estabilidade e a segurança de preservar renda em uma condição de vulnerabilidade que se busca assegurar. Em uma sociedade organizada em torno da produção e consumo de bens, a ausência de rendimentos quase sempre significa o rebaixamento social e a privação. No limite, além do infortúnio da doença, associa-se a exclusão do não pertencimento ao mundo do acesso ao consumo.

A avaliação da incapacidade ocorre na interface com o requerente. Através do exame médico, é feita a distinção entre aqueles que terão direito ao benefício ou não. A concessão depende também da regularidade da inscrição na Previdência Social e das contribuições previdenciárias, mas a distinção capaz x incapaz resultante do trabalho médico é elemento fundamental para o acesso a este direito. Os segurados da Previdência precisam comprovar estar doentes e impossibilitados para o exercício de atividade que lhes garanta renda (BRASIL, 2002), sendo competência legal do médico perito o reconhecimento ou não da incapacidade devido à doença (BRASIL, 2009a).

No contexto previdenciário, o ato médico ocorre sem que a conduta médica esteja voltada para o restabelecimento da saúde, tratamento ou prevenção do adoecimento. Não há compromisso assistencial. Contudo, os que buscam o benefício são, a princípio, doentes e alegam que em função das repercussões, das dimensões do sofrimento físico e/ou psíquico, não conseguem manter o trabalho que lhes garanta rendimentos. Estaríamos então diante da demanda de indivíduos duplamente vulneráveis, pelos efeitos do adoecimento associados à ausência de renda com potencial de exclusão e rebaixamento social.

A tarefa médico-pericial inclui anamnese, exame físico, leitura e interpretação de relatórios médicos e exames complementares e, além disso, ocorre nas dependências de consultórios nas Agências da Previdência Social - ou seja, possui 
todas as características do exame médico-assistencial, diferenciando-se quanto à natureza de sua finalidade. A ausência do compromisso assistencial seria então suficiente para prescindirmos do exame moral dessa interface?

Nesse sentido, consideramos legítimo e necessário empreender uma análise da relação médico-paciente na perspectiva dos conflitos morais que decorram da prática de controle de benefícios via exame médico pericial. Conflitos que se colocam em decorrência dessa posição específica, a exceção beneficente, onde ocorre a operação de verificação/escrutínio pericial, e tendo em vista uma noção de moralidade que "diz respeito ao indivíduo na sua singularidade" (ARENDT, 2004, p. 162). Exercício pleno do pensamento, reflexão que resulta em se abster do mal por ser sua própria companhia a mais exigente. Moralidade que não se confunde com costumes, normas ou códigos, com ser cumpridor, mas que inclui e considera seriamente no julgamento o pertencimento a uma comunidade e a capacidade de representar as consequências das açóes, onde a capacidade do julgamento está incluída (ARENDT, 2004). O trabalho médico-pericial já foi descrito como semelhante a um julgamento (MELO, ASSUNÇÃO, 2003).

Para esta trajetória, e ainda que provisoriamente, tomaremos emprestada a noção de risco, já disseminada no senso comum, conceitualmente oriunda da área da saúde e trabalho, e procuraremos trazer outros sentidos a esta noção, dialogando com conceitos como dano moral, conflito moral, conflito de interesses, sofrimento moral e lealdade dividida. Sem pretender esgotar as possibilidades mesmo para o percurso definido, neste artigo ${ }^{1}$ iremos desenvolver o argumento que a atividade médico-pericial de controle sobre a entrada e/ou permanência em benefício - a tarefa de gatekeeper do médico perito da Previdência Social (MARASCIULO, 2004) - envolve um tipo específico de risco que decorre da especificidade da tarefa de controle. Nesta, o compromisso com o paciente, ou pessoa em sofrimento, típico da medicina, é deslocado em decorrência da necessidade do controle de acesso. Entre a beneficência para com o demandante e o interesse coletivo de preservar recursos pela observância estrita do regramento previdenciário, há um espaço discricionário preenchido pela atividade médica, espaço deste arriscar-se, de tensionamento e, por vezes, de disfunções.

É preciso pôr em relevo, antes mesmo de prosseguirmos, que a relação médicopaciente na perícia médica é atravessada por interesses de atores relevantes no cenário econômico e político tais como empresas, sindicatos e o próprio Estado. As mais 
diversas relações entre esses atores criam uma trama complexa que, acreditamos, produz efeitos sobre a interface médico perito-segurado da Previdência Social, e são afetados por ela, na dimensão das repercussões sobre a massa da população segurada, alvo do cuidado previdenciário (FOUCAULT, 2005; 2008a). Ações sobre ações, sobre condutas, poder enquanto relaçôes de poder (FOUCAULT, 2013). A complexidade dessas interfaces exigiria uma análise detida sobre cada uma delas, trabalho que ultrapassa os limites agora propostos. Mesmo assim, ao longo do percurso não poderemos nos furtar a apontar elementos, de forma a manter fidelidade a um setting relacional que é determinado em sua origem pela macrotarefa de preservação da força de trabalho (GONÇALVES, 1992).

\section{(Im) Previdência?}

Previdência, saúde e assistência social compóem no Brasil o campo da seguridade social. Direito constitucional do capítulo dos direitos sociais (BRASIL, 1988), a política previdenciária tem a vida e suas intercorrências como alvo de cuidado e interferência do Estado. Enquanto biopolítica mostra o poder do Estado sobre a vida e o viver em seus efeitos de conjunto sobre a massa global da população, num exercício de poder político permanentemente atualizado e ajustado através de normas e regramentos administrativos (FOUCAULT, 2005, 2008a, 2008b; CASTELO BRANCO, 2013). De base contributiva ampla, abrange a atividade econômica nas mais diversas formas e fornece a seus segurados cobertura para eventos vitais como doença, velhice, morte, etc., em diversas modalidades de benefícios (BRASIL, 1991).

Organizada como um cofre coletivo compulsório, em regime de solidariedade contributiva, onde os que hoje trabalham pagam os benefícios dos que estão recebendo (BRASIL, 2009b), os recursos para os benefícios são dependentes das contribuições e taxações sobre a atividade econômica formal. Nesse ambiente macroeconômico, empresas, sindicatos e governo são atores interessados em um cenário de disputas quanto à definição das regras sobre direitos e obrigaçóes assim como em relação aos procedimentos de administração securitários.

O segurado da Previdência tem direito a receber o benefício o auxílio-doença enquanto permanecer doente e incapaz - melhor dizendo, enquanto o resultado da perícia médica reconhecer a existência de incapacidade para o trabalho. Em 2011, foram realizados 7,3 milhões de exames médicos periciais com $68,9 \%$ de 
conclusões favoráveis. As conclusões desfavoráveis se mantiveram em torno de $30 \%$ ao longo dos cinco anos anteriores (BRASIL, 2011)

A solvência do sistema previdenciário visa fazer frente aos compromissos assumidos e assegurar proteção para os futuros beneficiários, e depende também da gestão dos recursos. Quanto a isto, relatório de auditoria realizada pelo Tribunal de Contas da União (TCU) sobre a concessão e manutenção de benefícios auxílio-doença registra preocupação com o aumento das despesas causado por elevação expressiva das concessões no período 1998-2007. O relatório aponta um conjunto de elementos como determinantes na produção desta elevação, dentre os quais o aumento do número de segurados, a ampliação das Agências da Previdência Social, as alterações nas regras de aposentadoria com elevação da idade mínima e penalização financeira sobre aposentadorias em idades precoces, formas de cálculo do valor do benefício vantajosas em relação ao retorno ao trabalho, inconsistências nos sistemas informatizados de concessão e manutenção de benefícios, pouca efetividade e investimento institucional na área de reabilitação profissional e fatores relacionados à gestão da atividade médicopericial. Dentre estes, o TCU destacou a liberação da exigência de homologação de perícias realizadas por médicos terceirizados como fator para aumento das concessões (BRASIL, 2010).

Por outro lado, sabe-se que a grande maioria dos benefícios pagos pela Previdência no Brasil tem valor médio de menos de dois salários mínimos (BRASIL, 2013). A massa de pagamentos de benefícios previdenciários é fundamental na economia, configurando um diferencial importante na dinâmica econômica da maioria dos municípios brasileiros (BRASIL, 2012). Considerando sua relevância para o coletivo, como desconhecer sua representação, seu peso para cada um daqueles que solicitam o benefício? A tragédia que pode representar para a qualidade de vida de cada um, e de suas famílias, a impossibilidade de interagir plenamente na sociedade de trocas e consumo na qual vivemos?

\section{Entre Scyla e Caribdes: moralidade na interface de controle}

O senso comum nos indica que risco está relacionado à possibilidade, maior ou menor, de algo indesejável ocorrer. Tomamos como exemplo o risco de queda no trabalho em altura na construção civil. Percebemos que é intuitivo, e possível 
para todos os que observam, compreender que um trabalhador que realize seu trabalho num andaime a mais de 30 metros está submetido a um trabalho, ou tarefa específica, onde existe maior possibilidade de queda, com consequência sobre sua saúde e integridade física, do que se esse mesmo trabalhador estiver em alguma outra tarefa, ao nível do chão.

A chance de ocorrer um acidente em função da altura é maior na primeira situação de trabalho e seria inexistente na segunda. Para tornar mais clara nossa linha de argumentação, é preciso destacar que alguns riscos estarão presentes em ambas as situações como, p. ex., o risco ergonômico de estar submetido a posições desconfortáveis para o desempenho do trabalho.

Em relação à exposição ao risco de sofrer queda no trabalho em altura, as orientações protetoras para as tarefas que envolvam este risco estarão voltadas para minimizá-lo ou quiçá eliminá-lo. Então, conforme nosso exemplo, o risco está diretamente ligado à chance de um acontecimento (o acidente, a queda) ocorrer em função de uma situação de exposição (trabalho em altura). Neste caso, quanto maior o tempo em que este trabalhador fica exposto, maior será a chance de ocorrer o evento; quanto mais e melhores as medidas efetivamente adotadas para evitar a possibilidade de queda, menor será a possibilidade do dano (trauma) acontecer.

Assumindo como verdade que esse trabalho só possa ser executado nessas condiçōes, evitar a possibilidade da ocorrência do evento queda é solução para interferir, diminuindo ou eliminando, a chance do resultado indesejável (o trauma, ferimentos provocado pela queda) acontecer. Ainda assim, medidas podem ser adotadas para impedir as consequências de uma queda, evitando, por meio de medidas de contenção, que o trabalhador efetivamente atinja o chão produzindo ferimentos. Redes de proteção, cintos com dispositivos trava quedas, etc., são meios para esse segundo nível de proteção. $\mathrm{O}$ risco de queda com produção do dano continua ocorrendo, visto que a condição inicial, o trabalho em altura, persiste.

Ou seja, trabalho em altura é a condição em que a atividade ocorre e tal condição objetiva condiciona a chance maior ou menor de ocorrer o dano, segundo a forma como se organizam o trabalho e as medidas protetoras adotadas. $\mathrm{O}$ dimensionamento do risco ocupacional está vinculado à possibilidade de ocorrência do evento indesejável em função da condição em que o trabalho é realizado. Deve ficar claro que, no exemplo adotado, a única forma de eliminar 
o risco é eliminando a condição deste trabalho que é ser executado em altura. As demais alternativas gerenciam o risco, buscam diminuí-lo.

No exemplo do trabalhador hipotético da construção civil, não desconhecemos a existência e influência de macro determinações envolvendo sua exposição ao risco, sendo uma delas o custo da reparação acidentária, ou mesmo o jogo de forças que faz acidentes por queda em andaimes continuar ocorrendo. Ademais, as repercussões da sequência risco, evento, dano não se limitam ao ambiente laboral, ao acidentado, à empresa na qual ocorre o acidente. Os efeitos são compartilhados pela sociedade.

As facetas mais visíveis são os dias de afastamento, os benefícios auxíliodoença, mas a existência de um tipo de trabalho que é executado em condições que favorecem essa sequência coloca para todos a necessidade de indagar sobre responsabilidade coletiva (ARENDT, 2004). Para o caso dos benefícios auxíliodoença, adaptações e alterações nas exigências e quantidade de trabalho podem ser elementos facilitadores para evitar a sequência adoecimento-afastamento do trabalho, mas esses esforços podem ser entendidos pelas empresas como custo adicional e o uso do seguro previdenciário um cálculo planilhado, apesar de moralmente condenável.

Tomamos o exemplo esse recorte específico, por seu efeito didático. Considerando então esse exemplo para a categoria "risco" em geral, mas reconhecendo a especificidade que cada trabalho ou tarefa carrega, ficamos diante de nosso desafio: indagar sobre o risco moral presente na tarefa médicopericial de avaliação de incapacidade na interface médico perito-segurado. De antemão, compreendemos risco moral nessa atividade como algo inerente a ela, à semelhança do risco de queda no exemplo do trabalho em altura, como possibilidade de ocorrência de sofrimento, ou dano, determinado pelo exercício da tarefa, nas condiçôes em que esta é desenvolvida ou esteja organizada.

Outro ponto relevante é a intensidade ou forma de exposição ao risco. $\mathrm{Na}$ modelagem do controle de acesso atualmente praticado, o formato é sistemático exaustivo, ou seja, um a um dos segurados que solicitam benefício auxílio-doença, sua prorrogação, revisão ou contestam resultados de um atendimento, a cada requerimento, passam por avaliação médico-pericial. Como mencionamos anteriormente, em 2011 foram registrados 7,3 milhões de atendimentos médico-periciais. 
$\mathrm{Na}$ interface de avaliação sistemática da incapacidade há uma constante, o deslocamento do fim assistencial da medicina. O conhecimento, a expertise, a vivência profissional na medicina são necessárias para a avaliação, mas aquilo que representa a expectativa social da medicina está permanentemente excluído enquanto finalidade desse trabalho (SCHRAIBER, 2008). Entendemos este deslocamento como parte da natureza do trabalho médico-pericial, como aquilo que propicia o espaço em que se dá a operação de inclusãolexclusão realizada pelos peritos na tarefa de controle do acesso aos benefícios. Esta operação de verificação sobre a verdade dos corpos para o trabalho, de inclusão x exclusão, ocorre nesse espaço de controle sobre a vida, criado pelo deslocamento, onde se torna possivvel a exceção (AGAMBEM 2004). Exceção da beneficência como princípio moralmente válido para caracterizar esta tarefa (ALMEIDA, 2012).

Trata-se de uma operação biopolítica securitária (CASTELO BRANCO, 2013), em que a promoção da vida e a manutenção das forças se fazem por exclusão, separação dentro da própria população que, no limite, deixa a vida à mercê (DUARTE, 2006; FOUCAULT, 2009; 2005). Operação técnica que exige perícia em bem fazer a linha de corte, o enquadramento normativo, na junção da racionalidade médica à racionalidade jurídica (MELO, 2003). Essa operação produz uma tensão permanente que apresenta seus efeitos em diversas formas, das mais visíveis às mais subjetivas.

Reclamações sobre o atendimento médico-pericial registradas na Ouvidoria da Previdência Social podem ser entendidas como expressões das disfunções nesta interface. Excessos de poder, agressividade e humilhaçōes no trato com o segurado, dificuldades em lidar com a tarefa de controle estritamente centrada no ato médico, ficam evidentes na análise desses registros (MELO, 2014) Manifestaçôes de violência contra os peritos que chegam ao paroxismo de assassinatos (DUTRA, 2013) também podem ser compreendidas como disfunçôes extremas. Nos cotidianos de trabalho, os peritos médicos relatam temor e agressões verbais e físicas (BRASIL, 2009c).

Lidamos aqui com algo que ocorre em uma interface, na relação com um outro que demanda em função de uma carência, e tais efeitos serão possíveis para ambos os elos da interface: peritos e segurados. Existe na demanda uma especificidade, um interesse em suprir a carência ou reivindicação que tem um anteparo na interface. Como vimos, esta solicitação é atendida na maior parte 
das vezes. Mas nem sempre é assim. O controle médico sobre o benefício por incapacidade existe para realizar o ajuste dessa população demandante; desta forma, contradizer a expectativa de acesso é parte inerente [e esperada] da tarefa.

Significa, portanto, não atender à necessidade declarada de pessoas que têm doenças e que se sentem incapazes para auferir renda com o trabalho. Pessoas que muitas vezes têm grande necessidade do rendimento que poderia ser fornecido pelo benefício, mas não se enquadram. Que não se encaixam em quadros nosológicos, que não se ajustam ao mercado de trabalho. Enfim, são diversas as faces possíveis do não enquadramento. Estas exclusões sinalizam "um dispositivo de cobertura social [que] só beneficia plenamente o indivíduo integrado, seja em um meio familiar, em um meio de trabalho ou em meio geográfico" (FOUCAULT, 2010, p. 129).

O conflito entre o atendimento da demanda diante da vulnerabilidade dos requerentes e a observância estrita das normas é uma característica moralmente relevante da relação médico-paciente na perícia médica da Previdência Social (MELO, 2003). Para a pergunta moral que devo fazer, a resposta pronta é seguir as regras, mas sabe-se que estas mudam. A impermanência das regras é decorrente de sua natureza procedimental, por elas serem, ao menos em parte, resultado dos embates das forças políticas em ação neste campo, e da necessidade de ampliar ou restringir (mais comumente, restringir) direitos sob a justificativa administrativa da boa gestão econômica do sistema. Castelo-Branco (2013) contundentemente nomeia como "dupla chantagem" a caraterística dos sistemas securitários exigirem dos sujeitos, para inclusão e permanência, condutas e modos de vida enquadrados na ordem, assujeitamentos por assim dizer, e praticar a sistemática exclusão unilateral, com suas consequências, pela "alteração de regramentos administrativos, decisões burocráticas ou arbitragem médica” (CASTELO-BRANCO, 2013, p. 51).

Neste mesmo sentido, Stone (2011), em discussão sobre risco moral na perspectiva dos comportamentos de usuários de planos e sistemas de saúde, faz severas críticas. Para a autora, a expressão conduziria a um equívoco na medida em que, voluntariamente, os indivíduos não buscam procedimentos como quimioterapia, colonoscopia, hospitalização de longa permanência, etc., a necessidade clínica e não a vontade individual é que está em jogo. Destaca também que o consumo de procedimentos médicos é determinado por prescrições 
médicas e que o conceito distorce o poder decisório de indivíduos em condição de vulnerabilidade social, pois serão eles os primeiros a postergarem cuidados em saúde, na medida em que estiverem submetidos à obrigação de participação nos custos. Em tom de denúncia, afirma que o uso político do conceito transforma uma rede de proteção social, a seguridade, em ameaça e desproteção, e incita a sociedade ao perigo moral de deixar sem ajuda aqueles que mais necessitam dela.

O conceito de lealdade dividida diz respeito a conflitos presentes na relação médico-paciente diante de obrigações mútuas e a inclusão de um terceiro, como uma companhia de seguro, com quem se compartilhariam elementos oriundos da relação original (SINGH, 2003; PONT; STÖVER; WOLFF, 2012). Benatar e Upshur (2008) problematizam situações presentes no atendimento médico em ambiente militar, onde a lealdade ao Estado e à comunidade representada por este é posta em questão diante de condições-limite como alimentação forçada de prisioneiros em greve de fome, tratamento de intercorrências clínicas durante sessões de interrogatório, dentre outras. No entender desses autores, é relevante e necessário lançar um olhar crítico sobre esses e outros eventos em que a atuação médica é chamada a atender necessidades, inicialmente legítimas como a segurança pública.

O sistema de saúde, privado ou público, pode interagir a partir de seus polos de interesse e de sua lógica beneficente, fornecendo relatórios assistenciais que destaquem ou enfatizem a gravidade da condição clínica, até mesmo em função de dificuldades em apresentar soluçôes resolutivas, curativas, em vários casos (BRASIL, 2010). O exemplo das filas de espera para cirurgias ou da espera por atendimentos especializados no sistema de saúde é, infelizmente, do conhecimento de todos. Provavelmente muitos entre os beneficiários do auxílio-doença teriam seu tempo de duração do benefício diminuído caso não existissem tais problemas na rede assistencial. É possível também especularmos quanto aos efeitos que um sistema de saúde pautado pela qualidade da assistência pode ter na diminuição da morbidade geradora de incapacidade.

A análise custo $\mathrm{x}$ benefícios $\mathrm{x}$ efetividade no gerenciamento de sistemas de saúde é outro campo onde a limitação e o compromisso com os recursos a serem disponibilizados para o conjunto dos assistidos e o atendimento da demanda individual é alvo de diversos questionamentos, por vezes em um debate bastante 
tensionado. Nesse campo, o debate público contribui não somente com a avaliação das práticas de controle, como pode ser orientador para formulação e reformulação das políticas. Porém, tarefas que envolvam controle de recursos, autorização de procedimentos em saúde e similares quando exercidas na interface com os pacientes são sentidas pelos médicos como mais difíceis de ser desempenhadas quando comparadas à regulação macro sistêmica (CARLSEN; NORHEIM, 2005). Por outro lado, quais seriam os limites eticamente aceitáveis desde que eles, os limites, seriam necessários diante dos custos crescentes do setor saúde e dos limites orçamentários, e o que dizer desses custos (FOUCAULT, 2010)?

O compromisso com a regulação, com o desempenho baseado em normas, foi majoritariamente destacado por médicos peritos previdenciários em pesquisa que abordou o reconhecimento de princípios bioéticos na atividade profissional dos mesmos $\mathrm{O}$ princípio da justiça foi assinalado como valor predominante em detrimento da beneficência e não maleficência. No entanto, conforme concluiu o estudo, o fato de esses profissionais identificarem seu trabalho como vinculado ao princípio da justiça não garante que esse trabalho realmente contribua para que o valor "justiça” esteja presente no cotidiano dos requerentes aos benefícios (ALMEIDA, 2012).

A noção de justiça se relaciona àquilo que "é devido às pessoas, que de alguma forma lhes pertence ou corresponde” (FERRER; ALVAREZ, 2005, p. 138). Quanto ao princípio bioético de justiça, sua especificação ocorre primordialmente como tentativa de conferir um conteúdo razoável, justificado, à distribuição de recursos escassos, conferir materialidade à justiça no geral para torná-la distributiva (FERRER; ALVAREZ, 2005). Contudo, no caso da avaliação médico-pericial, o sentido dado pelos médicos peritos ao termo "justiça” parece estar relacionado à situação em exame, ao conjunto doença mais repercussões sobre a capacidade laborativa e à conformidade normativa aparentemente alcançada na decisão pericial.

Justo seria o encontro devido entre o caso presente no indivíduo em exame e o enquadramento. Portanto, não tem relação com uma ação, volitiva e mais ou menos adequada, de alocação de recursos escassos. Ideal inalcançável enquanto regra absoluta dado que a matéria do exame, a capacidade laborativa, é sujeita a variabilidade em seus aspectos biopsíquicos e sociais. Como elemento estrutural do ato administrativo (BINENBOJM, 2008) e médico, a discricionariedade 
está presente em cada exame e compõe, tensionando, a interface. Neste campo a noção de justiça, como uma imagem recorrente, se manifesta na ideia de imparcialidade, de fiel da balança; de não assumir compromisso parcial com o resultado, com qualquer dos lados, nem com a instituição ou com o segurado (MELO; ASSUNÇÃO, 2003).

No trabalho médico-pericial, não há incentivos econômicos ligados ao quantitativo de enquadramento favorável ou negativo, ou um limiar de concessão a ser alcançado ou evitado. O direito previdenciário ao auxílio-doença é concedido, nos moldes atuais, a todos os que se enquadrem na condição de segurados e incapazes. Sendo assim, o que parece ser devido é conceder benefício somente àqueles que reúnam o critério de elegibilidade, repercussão da doença sobre a normalidade biopsíquica a ponto de causar incapacidade para o exercício das suas atividades laborais. Reconhecer esta condição inequivocamente parece ser o ideal desse exercício profissional.

Diga-se de passagem, ideal relevante para os fins previdenciários. Basta verificar que no período 2001-2006, a elevação do patamar de concessões do auxílio-doença esteve relacionada ao desenvolvimento da atividade médicopericial por pessoal terceirizado na modalidade de pagamento por produtividade, e não sujeito a confirmação do resultado do procedimento pericial (homologação) por médicos do quadro próprio da Previdência Social (BRASIL, 2010).

Sabe-se que o trabalho realizado em condições de desacordo com os valores morais dos profissionais é gerador de sofrimento. Fథrde e Aasland (2008) em estudo sobre sofrimento moral entre médicos na Noruega citam problemas relacionados aos ambientes e à organização do trabalho como determinantes para a percepção de sofrimento. $\mathrm{O}$ trabalho em saúde tem o peso de um ideal profissional elevado e a exposição a uma vivência cotidiana permanentemente em conflito com esse ideal seria um dos componentes importantes para insatisfação entre esses trabalhadores. Os autores enfatizam ainda a falta de uma cultura de debate franco sobre a relevância dos aspectos éticos presentes no trabalho como fonte de insatisfação ou sofrimento.

$\mathrm{O}$ conflito diante da vulnerabilidade dos requerentes e a conduta esperada de cumprimento das normas, de realizar o enquadramento, de controlar o acesso, é uma característica moralmente relevante da relação médico-paciente na perícia médica da Previdência Social. Mesmo médicos peritos experientes 
relatam sofrimento diante de situações nas quais existe grande necessidade da renda do benefício, mas o segurado não se enquadra na avaliação de incapacidade (MELO; ASSUNÇÃO, 2003).

Lidar com a vulnerabilidade é próprio do exercício da medicina, e amenizá-la, realizar a cura ou minimizar o sofrimento, é o fim esperado pela sociedade para este exercício profissional. No caso do exercício médico-pericial, o reconhecimento da vulnerabilidade e o não atendimento ao comando hipocrático da beneficência podem ser faces da mesma moeda. Caminho estreito e arriscado.

\section{Para não concluir}

A Previdência é uma poupança coletiva, uma "caixinha" de contribuições diante de situações vitais que impliquem necessidade de proteção. Mas não só. Lastreada na população economicamente ativa, é fruto de um acordo, de um compromisso coletivo solidário onde o grupo contribui para proteger aquele entre eles que vivencia situação de vulnerabilidade. Enquanto esta perdurar. Contudo, suas implicações sobre a sociedade ultrapassam a proteção econômica do grupo estritamente protegido. Avança sobre a economia, a relação capital trabalho, a assistência à saúde e reabilitação e desafia a efetividade das políticas públicas, entre outros impactos. Por um lado, enquanto política social, o projeto previdenciário é proteger, mas em contrapartida essa proteção deve ter uma medida, um ajuste entre a proteção individual e os gastos de todos. Neste teorema se colocam conflitos e riscos.

A reflexão levada a cabo, longe de esgotar o tema, abre a clareira para a moralidade das políticas sociais como critério de avaliação e renovação das mesmas e alerta quanto à necessidade de estimular o reconhecimento dos constrangimentos éticos presentes na atividade médico-pericial. A nosso ver, é coerente com os elementos aqui destacados em torno da noção de risco moral arguir quanto ao sentido desta proteção previdenciária que se sustenta excluindo partes dos incluídos, partes da população segurada. Lembrando que as demandas securitárias têm um exponencial crescente de custos, é preciso também estabelecer um diálogo franco e responsável quanto ao nível de inclusão que concordamos em adotar, um diálogo periódico e nunca acabado (FOUCAULT, 2010). Talvez seja este o caminho adequado, mais justo e responsável, melhor do que delegar exclusivamente aos médicos esse papel. 
A especialização em reconhecer a incapacidade laborativa é moralmente conflitiva. A operação de escrutínio via exame médico estabelece no espaço da discricionariedade e do cuidado típicos da medicina abre uma exceção como via de funcionamento. Concordando com Arendt (2004), não há como prescindir, deixar de indagar sobre a moralidade enquanto responsabilidade individual e, deste ponto de vista, da consciência ética, admitir que não há sentido em argumentos como "dentes na engrenagem" para legitimar a reprodução irrefletida, quando lidamos com políticas sociais como a previdenciária. Políticas nas quais cada um dos assegurados e todos aqueles que estão fora da proteção compartilham um mundo. Mas no que tange à medicina, enquanto exercício profissional cabe também dirigir uma indagação a todos sobre o que queremos desse exercício médico.

De novo aqui, impor aos médicos a "escolha de Sofia" entre a proteção ao indivíduo, o exercício do cuidado, a segurança do Estado e o zelo medicalizado dos recursos, não carregaria os dedos além dos anéis? Mas, a quem mais delegar tal escrutínio? O peso das decisões, o temor de prejudicar, a emoção diante da necessidade e vulnerabilidade do outro, assim como as disfunções, falam de um lugar arriscado. Risco de banalizar a doença e a incapacidade, de fazer da exclusão o lugar comum, de se deixar instrumentalizar sem resistir, sem insistir em indagar para quê? Linha de produção, de inspeção médica.

Aqui, para nossa proteção, o pensamento, a reflexão ativa e o julgamento consciencioso devem substituir o trabalho burocratizado, de ninguém. Desta forma não se elimina o risco moral, mas tornamos evidentes as condições de sua emergência e a necessidade de considerá-lo seriamente ao lidar com essas práticas de controle sobre a população. Práticas médicas, engendramentos securitários, biopolítica.

\section{Referências}

AGAMBEM, G. Estado de exceção. São Paulo: Boitempo, 2004. 142p.

ALMEIDA, E.H.R. Aspectos bioéticos da perícia médica previdenciária. Revista Bioética, v. 19, n. 1, p. 277-298. 2011. Disponível em: <http://revistabioetica.cfm.org.br/index.php/ revista_bioetica/article/viewFile/618/637> Acesso em: 21. jan. 2012.

ARENDT, H. Responsabilidade e julgamento. São Paulo: Companhia das Letras, 2004. 375 p. BENATAR, S.R.; UPSHUR, R.E.G. Dual loyalty of physicians in military and in civilian life. American Journal of Public health, v. 98 n. 12, p. 2161-2167. Dec. 2008 
BINENBOJM, G. Direito administrativo. In: Temas de direito administrativo e

constitucional: artigos e pareceres. Rio de Janeiro: Renovar, 2008. p. 3-37.

BRASIL. Constituição da República Federativa do Brasil. Brasília, 1988. Disponível em: <http://www.planalto.gov.br/ccivil_03/constituicao/constitui\%C3\%A7ao.htm> Acesso em: 20 mar 2013.

BRASIL. Lei no 8.213, de 24 de julho de 1991. Dispõe sobre os Planos de Benefícios da Previdência Social. Disponível em: <http://www.ipsm.mg.gov.br/arquivos/legislacoes/ legislacao/leis/lei_8213.pdf> Acesso em: 22 mar 2013.

BRASIL. Ministério da Previdência Social. Anuário estatístico. Brasília: MPAS, 2011. Disponível em: <http://www.previdencia.gov.br/conteudoDinamico.php?id=423> Acesso em: 20 mar 2013.

BRASIL. Instituto Nacional do Seguro Social. Manual de Perícia Médica da Previdência Social. Brasília: INSS, 2002. Disponível em: <http://www.sindmedicos.org.br/juridico/ Manual\%20de\%20Pericias\%20Medicas\%20do\%20INSS.pdf > Acesso em: 04 mai. 2013.

BRASIL. Lei no 11.907, de 2 de fevereiro de 2009 (a). Disponível em: <http://www.planalto. gov.br/ccivil_03/_ato2007-2010/2009/Lei/L11907.htm> Acesso em: 20 mar 2013.

BRASIL. Ministério da Previdência Social. Previdência Social: reflexões e desafios. Brasília: MPAS, 2009(b). Disponível em: <http://www.previdencia.gov.br/arquivos/ office/3_100202-164641-248.pdf>. Acesso em: 22 mar 2013.

BRASIL. Instituto Nacional de Seguridade Social. Relatório final do Programa Nacional de Auditoria 2009: visão multifatorial do trabalho médico pericial. Brasília: INSS 2009(c). Mimeo.

BRASIL. Tribunal de Contas da União. Concessão e manutenção dos benefícios auxílio doença. Brasília: TCU, 2010. Disponível em: <http://portal2.tcu.gov.br/portal/page/portal/TCU/ comunidades/programas_governo/auditorias> Acesso em: 22 mar 2013.

BRASIL. Ministério da Previdência Social. Publicação do Ministério da Previdência Social. Ano II. No 4, set-dez 2012. Disponível em: <http://www.previdencia.gov.br/arquivos/ office/1_120918-105953-503.pdf> Acesso em: 03 jun 2013.

BRASIL. Ministério da Previdência Social. Tabela com valores médios dos benefícios pagos pelo INSS. Brasília: MPAS, 2013. Disponível em: <http://www.previdencia.gov.br/ conteudoDinamico.php?id=401 >. Acesso em: 03 jun 2013.

CARLSEN, B.; NORHEIM, O.F. "Saying no is no easy matter": a qualitative study of competing concerns in rationing decisions in general practice. BMC Health Services Research, v. 5, n. 70, Nov 2005. Disponível em:< http://www.biomedcentral.com/1472-6963/5/70> . Acesso em: 03 jun 2013.

CASTELO-BRANCO, G. A seguridade social em Michel Foucault. Revista ecopolitica, n. 5, jan.-abr./2013. Disponível em: <http://revistas.pucsp.br/index.php/ecopolitica/article/ view/14985/11183> Acesso em: 03 jun 2013. 
DUARTE, A. Biopolítica e resistência: o legado de Michel Foucault. In: RAGO, M.; VEIGA-NETO, A. (Orgs). Figuras de Foucault. Belo Horizonte: Autêntica, 2006. p. 45-55. DUTRA, B. Violência contra peritos, triste rotina na previdência. O Dia, Rio de Janeiro, 27 abr 2013. Seção economia. Disponível em: <http://odia.ig.com.br/portal/economia/ viol\%C3\%AAncia-contra-peritos-triste-rotina-na-previd\%C3\%AAncia-1.576441> Acesso em: 01 jun 2013.

FERRER, J.J.; ALVAREZ, J.C. Para fundamentar a bioética: teorias e paradigmas teóricos na bioética contemporânea. São Paulo: Loyola, 2005.

FÖRDE, R.; AASLANDE, O.G. Moral distress among Norwegian doctors. Journal of Medical Ethics, v. 34, n. 7, p. 521-525. 2008.

FOUCAUlT, M. Em defesa da sociedade: Curso no Collège de France (1975-1976). São Paulo: Martins Fontes, 2005.

FOUCAULT, M. Direito de morte e poder sobre a vida. In: História da sexualidade: a vontade de saber. São Paulo: Graal, 2009. p. 147-58.

Nascimento da biopolítica. Curso no Collège de France (1978-1979). São Paulo: Martins Fontes, 2008a.

Segurança, território, população. Curso no Collège de France (1977-1978). São Paulo: Martins Fontes, 2008b.

O sujeito e o poder. In: DREYFUS, H.L.; RABINOW, P. Michel Foucault: uma trajetória filosófica para além do estruturalismo e da hermenêutica. Rio de Janeiro: Forense Universitária, 2013. p. 273-295.

FOUCAULT, M. Um sistema finito diante de um questionamento infinito. In:

Ética, sexualidade, política. Rio de Janeiro: Forense Universitária, 2010, p. 126-143 (Coleção Ditos e Escritos V).

GONÇALVES, R.B. M. Práticas de saúde: processos de trabalho e necessidades. São Paulo: CEFOR, 1992. 51p.

MELO, M.P.P. Condiçôes do exercício profissional do médico perito da previdência social. Dissertação (Mestrado em Saúde Pública) - Faculdade de Medicina, Universidade Federal de Minas Gerais, Belo Horizonte, 2003.

MELO, M.P.P.; ASSUNÇÃO, A.A. A decisão médico pericial no âmbito da Previdência Social. Physis: Revista de Saúde Coletiva. Rio de Janeiro, v. 13, n. 2, p 343-65, 2003.

MELO, M.P.P. Governo da população: relação médico-paciente na pericia médica da previdência social. Interface - Comunicação, Saúde, Educação, v. 18, n. 48, p. 23-35. Jan./ Mar. 2014. Disponível em: http://www.scielo.br/scielo.php?script=sci_arttext\&pid=S1414$32832014000100023 \& \operatorname{lng}=\mathrm{pt} \& \mathrm{nrm}=\mathrm{iso} \& \mathrm{t} \operatorname{lng}=\mathrm{pt}$ 
MARASCIULO, A.C. E. Avaliação de desempenho do programa de benefícios por incapacidade do Instituto Nacional do Seguro Social: gerência de Florianópolis, SC, 20002002. Tese (Doutorado em Medicina)- Faculdade de Medicina, Universidade de São Paulo, São Paulo, 2004.

PONT, J.; STÖVER, H.; WOLFF, H. Dual loyalty in prision health care. Healty Police and Ethics, v. 102, n. 3, p. 475-480, March 2012.

SCHRAIBER, L.B. O médico e suas interações: a crise dos vínculos de confiança. São Paulo: Aderaldo \& Rothschild, 2008. 246p.

SINGH, J.A. American physicians and dual loyalty obligations in the "war on terror". BMC Medical Ethics, v. 4, n. 4. August 2003. Disponível em: <http://www.biomedcentral. com/1472-6939/4/4> Acesso em: 03 jun 2013.

STONE, D. Behind the jargon: moral hazard. Journal of Health Politics, Policy and Law, v. 36, n. 5, p. 886-896. October 2011.

\section{Notas}

${ }^{1}$ Este artigo apresenta reflexões resultantes da pesquisa Análise Bioética da relação médico-paciente na Perícia Médica da Previdência Social. O projeto desta pesquisa foi aprovado pelo Comitê de Ética em Pesquisa do Instituto de Medicina Social da Universidade do Estado do Rio de Janeiro - UERJ, registrado sob o CAAE 07893512.6.0000.5260. 


\section{Morality and risk in doctor-patient interface at medical expertise of Social Security}

Double vulnerability, disease and work disability: this condition must be verified by medical experts in the Brazilian Social Security system among those applying for sick leave benefits. In a society organized around the production and consumption of goods, lack of income often means downward social class mobility and social deprivation. In the context of Social Security, medical activity is not focused on health restoration, treatment or prevention of disease. However, would be the lack of focus on health care assistance an argument strong enough to ignore the moral exam of this patient-physician interface? Thus, this paper argues that the expert medical activity over the entry or stay on sick leave benefits involves a specific type of risk arising from the singularity of the control task. This commitment to the patient, typical of medicine, is shifted due the need to control access to benefit. Between beneficence towards the plaintiff and the collective interest of preserving resources for strict observance of pension rules, there is a discretionary space filled by medical activity, the space venture, tensioning and sometimes of malfunctions. Medical expertise in recognizing incapacity to work is morally conflictive. The active reflection and fair judgment do not eliminate the moral conflict, but the conditions of its emergence become more obvious as well as the need to consider moral conflicts seriously when dealing with these control practices over the population.

> Key words: bioethics; biopolitics; social security; moral conflict; forensic medicine; physician-patient relations. 